\title{
PERSONAL FACTORS DETERMINING THE EFFECTIVENESS OF SKILLED PLAYERS
}

\author{
Igor Presnyakov, Iossif Andruchsishin, Yury Denisenko,
}

Anatoly Geraskin, Denis Presnyakov

\begin{abstract}
The purpose of article is studying of personal features of the Kazakhstan tennis players and identification of their interrelations with efficiency of technical and tactical actions. In tennis, as well as in other sports, the victory depends not only on the level of physical, technical and functional fitness of the athlete, but also considerably on his psychological readiness, from his ability to operate the actions and behavior in the most difficult conditions of competitive fight, from timeliness of the choice of the correct decision, from realization of technical and tactical potential, that is from specific mental and psycho physiological features of the tennis player. The comparative analysis of the indicators reflecting personal features of athletes of various qualification is carried out. 12 strongest tennis players of Kazakhstan aged from 17 up to 23 years have participated in a research. The most significant properties of the personality on R. Cattell, which have made a personal profile of the Kazakhstan tennis player are revealed. High rates of sociability (factor A), emotional steadiness (factor C), tendencies to domination (E factor), activities (factor H), Bohemianism (factor $M)$, strong-willed self-checking $\left(Q_{3}\right.$ factor), and also low indicators of a secondary factor of $F_{4}$, concern to them. Efficiency of technical and tactical actions: the quantity of aces, quantity of double mistakes on service hit percent in a square of the first service, hit percent in a square of the second service, the number of the won draws for a match, percent of the points realized a break, percent of the points won from the first service, percent of the points won from the second service, accepted service in a match, was determined by indicators. Average arithmetic has been revealed on all indicators. Reliable correlations of efficiency of game actions with factors $G, H, M, F_{3}, F_{4}$ and TT (tendency to traumatism) are revealed.Keywords: the technical and tactical actions, efficiency of activities, personal characteristics, personal profile and model characteristics.
\end{abstract}

Introduction. The tennis in competitive execution of the best players of the world is the sport imposing the strictest requirements not only to various parties of training of athletes: physical, technical, tactical, integrated, psychological, but also to morphometric indicators. And it isn't casual, duration of matches of rivals, equal on forces, can reach till three and more hours. To sustain such tennis marathon are necessary an enormous stock not only muscular endurance, but also psychological stability, ability to cope with the ultra boundary mental tension which, as a rule, accompanies matches of this sort, ability to cope with the quantity of mistakes increasing by the end of a match and to adequately accept joy of a victory and bitterness of defeat after the end of a game. And it, first of all, a consequence of violation of activity of mental mechanisms of physical action, but not physical exhaustion and fatigue is as usual considered to be increase of number of mistakes. The researchers conducted in sport psychology demonstrate that earlier exhaustion of mental mechanisms is caused by the fact that they are less trained, than muscles. Training process is direct- ed, first of all, for work with muscular system and purposeful impact on mental mechanisms doesn't assume. Therefore in the course of competitive activity failures (mistakes) begin to arise in the least trained system, i.e. in mental mechanisms of motive activity, and they, in turn, are connected with other psychological variables and including with personal properties $[2,3]$.From told follows that the efficiency of competitive activity is definitely connected with properties of the identity of the athlete. Works where communications between efficiency of competitive activity of tennis players and properties of their personality would reveal, in psychology and pedagogical literature known to us aren't revealed and it defines relevance of the conducted research.

The purpose of article is studying of personal features of the Kazakhstan tennis players of high qualification and identification of their interrelations with efficiency of competitive technical and tactical actions.

Research methodology. In the course of the re- 
search the following methods were used: calculation of number of the technical and tactical actions fixed in official protocols of a game. The efficiency of technical and tactical actions came was carried out on indicators: the quantity of aces (the balls won directly from service), quantity of double mistakes on service, percent of the first service, percent of the second service, the number of the won draws for a match, percent of the realized break points, percent of the points won from the first service, percent of the points won from the second service, quantity accepted service in a match. 200 protocols of a game of the Kazakhstan tennis players, from 20 to 23 official protocols of each player have been analyzed and average values are calculated. At foreign tennis players 15 official protocols on each player are analyzed and also average values are calculated. For studying of properties of the personality the computer version of the 16 -factorial personal test of R. Cattell, developed by N.V. Tipatov was used (this decision is realized within the Excel on service of HR program).
Processing of results of a research was carried out with application of methods of mathematical statistics: calculation of arithmetic-mean size (), a standard deviation $(\sigma)$ and the correlation analysis according to Pearson.

12 strongest Kazakhstan tennis players aged from 17 up to 23 years which are a part of the national and junior national teams of the Republic of Kazakhstan and participating in ITF tournaments and the Davis Cup, participated in a research.

Results of a research. From table 1 where indicators according to R. Cattell's test are presented, it is visible that in a personal profile of tennis players on primary factors high rates of the following lines most are considerably allocated: sociability (And - 7,2 points), emotional steadiness (With - 7,5 points), tendencies to domination ( $\mathrm{E}-7,3$ points), activities ( $\mathrm{H}-7,8$ points), Bohemianisms ( $M$ - 7,2 points), strong-willed self-checking $\left(\mathrm{Q}_{3}-\right.$ 7,3 points); on secondary factors - ekstraversiya ( $\mathrm{F}_{2}-8,0$ points).

Table 1

Indicators of age, experience of occupations tennis and personal properties of the strongest Kazakhstan tennis players according to R. Cattell's test

\begin{tabular}{|c|c|c|c|c|c|c|c|c|c|c|c|c|c|c|c|c|c|c|c|c|c|c|}
\hline 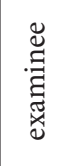 & $\underset{\infty}{\infty}$ & 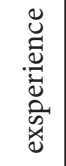 & A & B & $\mathrm{C}$ & E & $\mathrm{F}$ & $\mathrm{G}$ & $\mathrm{H}$ & I & $\mathrm{L}$ & $\mathrm{M}$ & $\mathrm{N}$ & $\mathrm{O}$ & $\mathrm{Q}_{1}$ & $\mathrm{Q}_{2}$ & $\mathrm{Q}_{3}$ & $\mathrm{Q}_{4}$ & $\mathrm{~F}_{1}$ & $\mathrm{~F}_{2}$ & $\mathrm{~F}_{3}$ & $\mathrm{~F}_{4}$ \\
\hline L-n & 18 & 11 & 8 & 4 & 9 & 9 & 6 & 4 & 8 & 8 & 7 & 9 & 6 & 3 & 1 & 7 & 8 & 3 & 2,3 & 8,2 & 4,3 & 7 \\
\hline E-v & 17 & 12 & 8 & 5 & 8 & 7 & 6 & 7 & 7 & 8 & 7 & 5 & 5 & 3 & 6 & 6 & 9 & 1 & 1,7 & 7,3 & 4,3 & 6 \\
\hline G-v & 16 & 13 & 6 & 5 & 8 & 10 & 8 & 4 & 9 & 7 & 8 & 10 & 4 & 3 & 5 & 5 & 6 & 3 & 2,9 & 9,8 & 6,1 & 9 \\
\hline D-v & 17 & 11 & 6 & 8 & 6 & 5 & 5 & 5 & 8 & 5 & 9 & 8 & 2 & 6 & 6 & 6 & 7 & 10 & 7,2 & 6,4 & 5,5 & 7 \\
\hline S-V & 18 & 12 & 7 & 9 & 8 & 5 & 4 & 5 & 6 & 6 & 4 & 1 & 7 & 4 & 9 & 6 & 6 & 5 & 3,8 & 5,2 & 5,7 & 5 \\
\hline $\mathrm{P}-\mathrm{O}$ & 20 & 13 & 7 & 4 & 8 & 7 & 8 & 4 & 10 & 8 & 6 & 9 & 3 & 4 & 1 & 5 & 9 & 3 & 2,0 & 9,6 & 4,9 & 6 \\
\hline Ev-v & 23 & 17 & 10 & 9 & 8 & 7 & 9 & 5 & 8 & 6 & 3 & 7 & 3 & 4 & 9 & 6 & 10 & 3 & 1,6 & 9,4 & 5,1 & 6 \\
\hline K-n & 19 & 13 & 6 & 6 & 8 & 7 & 7 & 4 & 7 & 3 & 3 & 8 & 6 & 3 & 4 & 5 & 8 & 3 & 1,9 & 7,5 & 7,7 & 6 \\
\hline M-o & 18 & 13 & 8 & 8 & 5 & 5 & 6 & 6 & 7 & 7 & 7 & 6 & 2 & 8 & 6 & 7 & 9 & 10 & 7,4 & 6,5 & 3,7 & 6 \\
\hline A-p & 21 & 15 & 7 & 2 & 8 & 10 & 8 & 4 & 9 & 8 & 7 & 10 & 3 & 3 & 4 & 5 & 6 & 4 & 3,1 & 10 & 5,1 & 8 \\
\hline $\mathrm{H}-\mathrm{n}$ & 21 & 15 & 7 & 4 & 7 & 6 & 9 & 2 & 6 & 5 & 7 & 7 & 3 & 4 & 4 & 3 & 5 & 6 & 5,2 & 8,1 & 6,1 & 6 \\
\hline $\mathrm{K}-\mathrm{a}$ & 21 & 16 & 6 & 2 & 7 & 9 & 7 & 5 & 8 & 4 & 8 & 6 & 6 & 3 & 6 & 6 & 4 & 5 & 4,5 & 8,4 & 7,9 & 8 \\
\hline & 19,1 & 13,4 & 7,2 & 5,5 & 7,5 & 7,3 & 6,9 & 4,6 & 7,8 & 6,3 & 6,3 & 7,2 & 4,2 & 4,0 & 5,1 & 5,6 & 7,3 & 4,7 & 3,6 & 8,0 & 5,5 & 6,5 \\
\hline$\sigma$ & 2,11 & 1,93 & 1,19 & 2,50 & 1,09 & 1,86 & 1,56 & 1,24 & 1,22 & 1,71 & 1,97 & 2,52 & 1,75 & 1,54 & 2,54 & 1,08 & 1,86 & 2,81 & 2,05 & 1,52 & 1,28 & 1,34 \\
\hline
\end{tabular}

Considering high expressiveness of average values, it is possible to believe that the marked-out properties of the personality can be relevant model characteristics of the identity of the Kazakhstan tennis players.
From table 2 where average values of efficiency of technical and tactical actions of the Kazakhstan tennis players and their foreign peers are presented, differences between them are visible. On two registered indicators from nine, advantage on the party of the Kazakhstan tennis players. It is percent of the hit from 
the first service $-62,1 \%$. Foreign tennis players have $56,6 \%$, i.e. is $5,5 \%$ less. Less the Kazakhstan tennis players have also a quantity of double mistakes on service $-1,5$ during the match. Foreign peers make 2,4 mistakes during the match. On other seven

Table 2

Average values of efficiency of technical and tactical actions of the strongest Kazakhstan $(n=9)$ and foreign tennis players $(n=10)$

\begin{tabular}{|c|c|c|c|c|c|c|c|c|c|}
\hline Examinee & 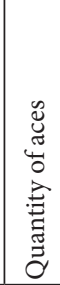 & 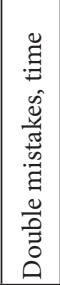 & 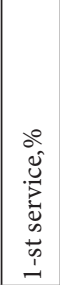 & 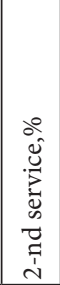 & 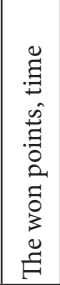 & 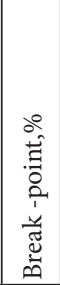 & 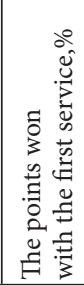 & 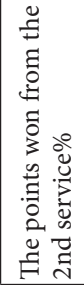 & 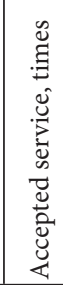 \\
\hline $\begin{array}{l}\text { Kazakl } \\
\text { tennis }\end{array}$ & 1,0 & 1,5 & 62,1 & 90,2 & 28,0 & 20,8 & 59,0 & 40,3 & 29,2 \\
\hline $\begin{array}{l}\text { Foreign } \\
\text { tennis playe }\end{array}$ & 4,1 & 2,4 & 56,6 & 92,5 & 71,9 & 42,6 & 71,4 & 52,6 & 63,1 \\
\hline
\end{tabular}

indicators (to quantity: aces, the won draws and the accepted service; to percent: the given second service, break points, the first and second service) advantage on the side of the peers who are in the ITF tournaments. Especially the Kazakhstan tennis players by the number of the won draws during the match lag behind. 71,9 points are won for a match by foreign tennis players and only 28 points tennis players of Kazakhstan. Proceeding from the submitted data on the number of the won draws, it is possible to say that significant improvement of this indicator will affect the world ranking not only certain players positively, but also all Kazakhstan tennis [4].
Discussion of results. The revealed interrelations between indicators of efficiency of technical and tactical actions and personal properties with application of the correlation analysis according to Pearson, are presented in table 3 .

The following fact attracts attention. Such important indicators of game activity as percent hits of the first service in a zone of reception, the won break points and points won from the second service and also the number of the won draws haven't found interrelations with properties of the personality on P. Kattell. Most likely this circumstance can be explained with the insufficient volume of selection, considering that on other game indicators of correlation are available. If to speak about other five indicators of game actions, here the greatest numbers of correlation communications are revealed by double mistakes and the accepted service, in other words these two indicators are most closely connected with personal properties of tennis players. Analyzing these communications we see, the Bohemianism, pensiveness, a separation from reality and immersion in the internal interests (the $\mathrm{M}$ factor) is higher, the more tennis players makes double mistakes on service $(r=0,740 ; P<0,01)$. Thus there are bases to claim that high values on the $\mathrm{M}$ factor, negatively affect efficiency of game activity. Desire to be independent, aggressive, sharp (a secondary factor of $\mathrm{F}_{4}$ ), leads to increase in double mistakes on service, but at the same time reduces the number of the second service $(r=0,629 ; \mathrm{P}<0,05)$.

Table 3

Correlation communications between indicators of personal properties and efficiency of technical and tactical actions of the strongest Kazakhstan tennis players $(n=9)$

\begin{tabular}{|c|c|c|c|c|c|c|c|c|c|}
\hline $\begin{array}{l}\text { Factors of } \\
\text { the test of } \\
\text { R. Cattell }\end{array}$ & 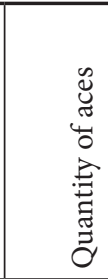 & 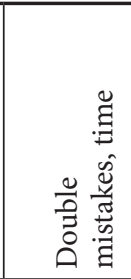 & 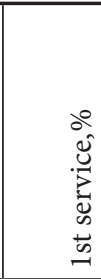 & 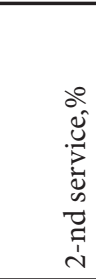 & 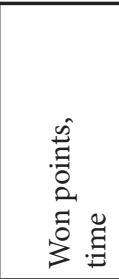 & 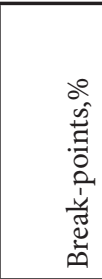 & 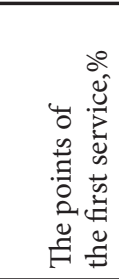 & 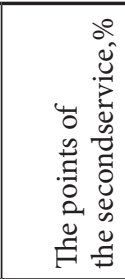 & 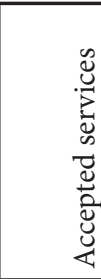 \\
\hline A & $-0,188$ & $-0,332$ & 0,505 & 0,193 & 0,261 & 0,019 & 0,167 & $-0,069$ & $-0,277$ \\
\hline B & $-0,484$ & $-0,063$ & 0,448 & 0,005 & 0,194 & 0,286 & $-0,300$ & $-0,422$ & $-0,176$ \\
\hline $\mathrm{C}$ & 0,274 & 0,133 & 0,121 & 0,080 & $-0,284$ & $-0,296$ & 0,066 & 0,083 & $-0,292$ \\
\hline $\mathrm{E}$ & 0,093 & 0,469 & $-0,185$ & $-0,401$ & $-0,276$ & $-0,180$ & 0,022 & 0,380 & $-0,107$ \\
\hline$F$ & 0,101 & 0,244 & 0,435 & $-0,058$ & 0,221 & $-0,320$ & 0,393 & 0,194 & $-0,071$ \\
\hline G & $-0,568$ & $-0,454$ & \begin{tabular}{|l|}
$-0,263$ \\
\end{tabular} & 0,074 & $-0,198$ & 0,710 & $-0,667^{*}$ & $-0,246$ & $-0,109$ \\
\hline $\mathrm{H}$ & $-0,084$ & 0,446 & $-0,060$ & $-0,290$ & $-0,170$ & \begin{tabular}{|l|}
0,311 \\
\end{tabular} & $-0,237$ & 0,268 & $-0,643^{\star}$ \\
\hline I & $-0,160$ & 0,059 & $-0,244$ & $-0,363$ & $-0,381$ & 0,126 & $-0,066$ & 0,143 & $-0,643^{\star}$ \\
\hline $\mathrm{L}$ & $-0,168$ & 0,112 & $-0,418$ & $-0,422$ & 0,013 & 0,223 & $-0,066$ & 0,094 & 0,129 \\
\hline
\end{tabular}




\begin{tabular}{|l|l|l|l|l|l|l|l|l|l|}
\hline $\mathrm{M}$ & 0,160 & $0,740^{* *}$ & 0,013 & $-0,531$ & $-0,276$ & $-0,247$ & 0,102 & 0,421 & $-0,387$ \\
\hline $\mathrm{N}$ & $-0,237$ & $-0,033$ & $-0,259$ & 0,328 & $-0,247$ & $-0,346$ & 0,084 & $-0,212$ & 0,245 \\
\hline $\mathrm{O}$ & $-0,237$ & $-0,237$ & $-0,005$ & $-0,090$ & 0,215 & 0,228 & $-0,109$ & $-0,152$ & 0,020 \\
\hline $\mathrm{Q}_{1}$ & $-0,761^{\star *}$ & $-0,260$ & 0,417 & $-0,073$ & 0,395 & 0,541 & $-0,204$ & $-0,075$ & 0,179 \\
\hline $\mathrm{Q}_{2}$ & $-0,194$ & $-0,097$ & $-0,119$ & 0,029 & $-0,026$ & 0,312 & $-0,377$ & $-0,075$ & 0,051 \\
\hline $\mathrm{Q}_{3}$ & $-0,186$ & $-0,186$ & 0,174 & 0,229 & $-0,213$ & 0,211 & $-0,410$ & $-0,164$ & $-0,466$ \\
\hline $\mathrm{Q}$ & $-0,131$ & 0,022 & 0,020 & $-0,143$ & 0,389 & 0,141 & 0,153 & 0,076 & 0,283 \\
\hline $\mathrm{F}_{1}$ & $-0,141$ & $-0,001$ & $-0,102$ & $-0,192$ & 0,349 & 0,129 & 0,174 & 0,047 & 0,308 \\
\hline $\mathrm{F}_{2}$ & 0,041 & 0,448 & 0,194 & $-0,288$ & $-0,045$ & $-0,122$ & 0,165 & 0,374 & $-0,185$ \\
\hline $\mathrm{F}_{3}$ & 0,235 & 0,164 & 0,050 & 0,197 & 0,170 & $-0,155$ & 0,025 & 0,006 & $0,603^{*}$ \\
\hline $\mathrm{F}_{4}$ & $-0,237$ & $0,629^{*}$ & $-0,128$ & $-0,685^{*}$ & $-0,091$ & 0,100 & $-0,050$ & 0,406 & 0,027 \\
\hline $\mathrm{F} / \mathrm{d}$ & 0,199 & 0,026 & $-0,405$ & $-0,064$ & $-0,514$ & $-0,154$ & $-0,139$ & $-0,037$ & $-0,367$ \\
\hline $\mathrm{C} / \mathrm{m}$ & $-0,202$ & 0,032 & $-0,139$ & $-0,254$ & 0,281 & 0,224 & 0,094 & 0,030 & 0,206 \\
\hline $\mathrm{P} / \mathrm{h}$ & 0,198 & 0,084 & 0,108 & 0,095 & $-0,248$ & $-0,252$ & 0,046 & 0,061 & $-0,211$ \\
\hline $\mathrm{TT}$ & $-0,295$ & $-0,623^{*}$ & $-0,067$ & 0,422 & $-0,169$ & 0,395 & $-0,483$ & $-0,435$ & $-0,079$ \\
\hline $\mathrm{T} / \mathrm{t}$ & $-0,455$ & $-0,292$ & 0,090 & 0,120 & $-0,096$ & 0,465 & $-0,553$ & $-0,425$ & $-0,242$ \\
\hline $\mathrm{SB}$ & $-0,352$ & $-0,225$ & 0,046 & 0,118 & $-0,257$ & 0,356 & $-0,547$ & $-0,228$ & $-0,246$ \\
\hline
\end{tabular}

These are tennis players of the first service, who - ness of the principles and representations. the first service seek to solve at once a problem and therefore as much as possible invest in the first service, risk, by the principle "Win or lose". From this it follows that excessively expressed aggression and sharpness interferes with improvement of efficiency of technical and tactical actions of players.

Also negatively increase in indicators of tendency to traumatism (a factor of the third order - TT) which is a consequence of risky behavior $(\mathrm{r}=-$ $0,623$ affects quality of game activity; $\mathrm{P}<0,05)$, in other words, the less risks the tennis player, the less he allows double mistakes onservice.

What shakes the accepted service, here negative correlation communication demonstrates that high rates of activity, courage of the tennis player $(\mathrm{H}$ factor), will reduce efficiency of reception of service $(r=-0,643 ; \mathrm{P}<0,05)$. The psikhastenichnost of players (a factor of I) will affect the same way efficiency of a game. The sensitivity and artistry of nature of the tennis player are higher, the worse he accepts service, each failure very strongly upsets him and he can badly gather for the next reception $(r=-0,643 ; P<0,05)$. At the same time the aspiration of tennis players to work quickly, resolutely, without any doubts ( $\mathrm{F}_{3}$ factor) promotes increase in efficiency of reception of service $(r=-0,603$; $\mathrm{P}<$ $0,05)$.

It is positively connected with winning of service (aces) property of conservatism $\left(\mathrm{Q}_{1}\right.$ factor). The more at the tennis player the tendency to conservatism is developed, the it is more at him than wonofservice. It is promoted by his conviction in correct-

Improvement of efficiency of game actions is promoted by decrease in social dominance ( $G$ factor). The more originally and more freely, the tennis player acts and the less he is subject to influence of social norms and requirements, the points from the first service are won more $(r=-0,761 ; P<0,01)$.

High rates of a secondary factor of $\mathrm{F}_{4}$ (independence, aggression, sharpness) have an adverse effect on quality of the second service $(r=-0,685$; $P$ $<0,05)$, i.e. decreases percent of the second service.

It is necessary to pay attention to the next moment. From those factors which are connected with efficiency of technical and tactical actions only two (high rates of Bohemianism - $\mathrm{M}$ and activities N) are among properties of the personality which belong to the relevant model characteristics of the Kazakhstan tennis players selected with us. According to V.E. Milman's research if properties of the personality are connected with efficiency of activity, then they have to be special structure of the identity of tennis players [1]. It is necessary to notice that high values of these factors have negative effect on efficiency of activity of tennis players. In the same work Milman also claims that in acyclic sports there are properties of the personality, which positively influence activity of athletes, and there are those which have an adverse effect on motive activity in this or that sport.

Conclusions.1. Relevant model characteristics of the identity of the strongest Kazakhstan tennis players are defined. The following personal factors 
have entered her with high values: sociability $(A)$, emotional steadiness (C), tendency to domination $(\mathrm{E})$, activity $(\mathrm{N})$, Bohemianism $(\mathrm{M})$, strong-willed self-checking $\left(Q_{3}\right)$, ekstraversiya $\left(F_{2}\right) .2$. Superiority of the Kazakhstan tennis players in efficiency of the first service and smaller quantity of double mistakes on service, and lag from foreign peers in quantity is revealed: aces, the won draws and the accepted service and also on percent of second service, break points, the first and second service. The greatest lag is available for the Kazakhstan tennis players by the number of the won draws during the match that prevents them to achieve the same results as at foreign peers.

3. Positive correlation communications of efficiency of technical and tactical actions with such personal properties as jet steadiness $\left(\mathrm{F}_{3}\right)$, conservatism $\left(Q_{1}\right)$, the reduced level of social dominance $(G)$ and negative communications with Bohemianism (M), independence of behavior $\left(\mathrm{F}_{4}\right)$, tendency to traumatism (TT), activity $(\mathrm{H})$ and a psikhastenichnost (I) are found.

4. It is revealed that such properties of the personality as the Bohemianism (M) and activity (H) which are special structure of the identity of tennis players negatively influence efficiency of their activity.

\section{Literature}

Milman B.E. Stress i lichnostnye factory v regulyatsii deyatelnosty //Stress i trevoga v sporte: Mezhdunarodnyi sb. Naychnykh statei /Sost. Y.L. Khanin.- M.: Fizkultyra i sport, 1983.- S. 24-46.

Nemov R. S. Uchebnik dlya studentov vysshykh ped.. uchebnykh zavedenii: V $3 \mathrm{Kn}$. Kn. 1. Obshchie osnovy psikhologii.- 3-e izd.- M.: Gumanit. izd. Tsentr VLADOS, 1997.- S. 8-12.

Psikhologiya sporta vysshykh dostizhenii: ucheb. posobie dlya ins-tov fiz.kult. /Pod red. A. V. Rodionova.- M.: Fizkultura i sport, 1979.- $144 \mathrm{~s}$.

https://www.SofaScore.com. 